\title{
Altered Precipitation Impacts on Above- and Below-Ground Grassland Invertebrates: Summer Drought Leads to Outbreaks in Spring
}

\author{
Marcel D. Torode ${ }^{1,2 *}$, Kirk L. Barnett ${ }^{2}$, Sarah L. Facey², Uffe N. Nielsen ${ }^{2}$, Sally A. Power \\ and Scott N. Johnson ${ }^{2}$ \\ ${ }^{1}$ School of Biosciences, Cardiff University, Cardiff, UK, ${ }^{2}$ Hawkesbury Institute for the Environment, Western Sydney \\ University, Richmond, NSW, Australia
}

\section{OPEN ACCESS}

Edited by: Michael Rostás, Lincoln University, New Zealand

Reviewed by: Fernando José Cebola Lidon, Universidade Nova de Lisboa,

Portugal

Mukhtar Ahmed,

Pir Mehr Ali Shah Arid Agriculture

University, Pakistan

${ }^{*}$ Correspondence:

Marcel D. Torode torodeM@cardiff.ac.uk

Specialty section:

This article was submitted to Agroecology and Land Use Systems, a section of the journal

Frontiers in Plant Science

Received: 04 July 2016 Accepted: 15 September 2016 Published: 06 October 2016

Citation:

Torode MD, Barnett KL, Facey SL, Nielsen UN, Power SA and Johnson SN (2016) Altered Precipitation Impacts on Aboveand Below-Ground Grassland Invertebrates: Summer Drought Leads to Outbreaks in Spring.

Front. Plant Sci. 7:1468. doi: 10.3389/fpls.2016.01468
Climate change is predicted to result in altered precipitation patterns, which may reshape many grassland ecosystems. Rainfall is expected to change in a number of different ways, ranging from periods of prolonged drought to extreme precipitation events, yet there are few community wide studies to accurately simulate future changes. We aimed to test how above- and below-ground grassland invertebrate populations were affected by contrasting future rainfall scenarios. We subjected a grassland community to potential future rainfall scenarios including ambient, increased amount ( $+50 \%$ of ambient), reduced amount ( $-50 \%$ of ambient), reduced frequency (no water for 21 days, followed by the total ambient rainfall applied in a single application) and summer drought (no rainfall for 13 weeks during the growing season). During Austral spring (September 2015), we sampled aboveground invertebrates, belowground macro invertebrates and nematodes. Aboveground communities showed a significant response to altered rainfall regime with the greatest effects observed in summer drought plots. This was mostly due to a large increase in sucking herbivores (658\% higher than ambient plots). Plots experiencing summer droughts also had higher populations of parasitoids, chewing herbivores and detritivores. These plots had $92 \%$ more plant biomass suggesting that primary productivity increased rapidly following the end of the summer drought 5 months earlier. We interpret these results as supporting the plant vigor hypothesis (i.e., that rapid plant growth is beneficial to aboveground invertebrates). While belowground invertebrates were less responsive to altered precipitation, we observed a number of correlations between the abundances of above- and below-ground invertebrate groups under ambient rainfall that dissipated under altered rainfall regimes. Mechanisms underpinning these associations, and reasons for them to become decoupled under altered precipitation regimes (we term this 'climatic decoupling'), remain speculative, but they provide the basis for formulating hypotheses and future work. In conclusion, we predict that shifts in rainfall patterns, especially summer drought, will likely have large, but probably short-term, impacts on grassland invertebrate communities. In particular, sucking herbivores show sensitivity to precipitation changes, which have the potential to cascade through the food chain and affect higher trophic levels.

Keywords: aboveground-belowground interactions, arthropods, climate change, multi-trophic interactions, rainfall extremes, root herbivores, soils 


\section{INTRODUCTION}

Invertebrates make up $96 \%$ of known terrestrial species, with an estimated contribution to ecosystem services worth $\$ 60$ billion per year in the US alone (Losey and Vaughan, 2006). Invertebrates are the main faunal component of grassland ecosystems and key to ecosystem functioning, contributing to services such as soil formation, pollination and population control (Curry, 1994; Weisser and Siemann, 2004). Grasslands are globally important ecosystems, underpinning livestock production and regulating our climate (Gibson, 2009), with carbon sequestration by grasslands estimated to be worth over $\$ 200$ per hectare (Daily, 1997).

Climate change models predict altered precipitation patterns and an increased number of extreme precipitation events (IPCC, 2014), which will likely impact grasslands and the invertebrates within them. Changes in rainfall could be highly variable. For example, Australian rainfall records have shown recent increases in wet and dry extremes as well as greater seasonal variation, thought to be partly explained by climate change (Garnaut, 2011). Altered rainfall patterns can have direct effects on invertebrates, such as heavy rainfall events causing physical damage during flight, to reducing foraging efficiency and increasing migration times (Barnett and Facey, 2016). On the other hand, droughts can cause desiccation of above- and below-ground invertebrates, often decreasing the viability and survival of the eggs and larvae (e.g., Johnson et al., 2010; Gantz and Lee, 2015). Predicting the impacts of changes in rainfall on invertebrate communities is complicated by the fact that altered rainfall is unlikely to affect all invertebrates in the same way. For example, the impact of drought on soft bodied invertebrates, such as isopods and myriapods, is likely to be greater than the effects on arachnids and insects which have a waxy cuticle that serves to reduce water loss (Berridge, 2012).

Indirect effects of water stress, such as those mediated by plants, can also affect invertebrates differently (Koricheva et al., 1998). Sucking herbivores, for example, may benefit from an increased concentration of nitrogenous compounds in plant foliage following water stress, but only when plants enter a recovery phase (i.e., turgor pressure returns). Huberty and Denno (2004) termed this the 'pulsed-stress hypothesis', but also noted that increased levels of plant defensive compounds following water stress often reduce the abundance of chewing herbivores. In contrast, the plant vigor hypothesis has been proposed based on observations that some phytophagous insects choose vigorous, fast-growing parts of plants to feed on (Price, 1991). Fast growing plant tissue is thought to have higher nutrient availability, greater osmotic potential and be relatively low in fiber and lignified tissue (Price, 1991, 2003). Decreased rainfall or altered patterns of rainfall, causing plant dieback, might subsequently stimulate such vigorous re-growth of some plant species when precipitation patterns return to ambient levels.

The group or guild specific responses of invertebrates to altered precipitation patterns are likely to alter the interactions occurring between species, and subsequently the structure of communities (Voigt et al., 2003). Yet, relatively few studies explore the impact of climate change at the community level, with still fewer including both above- and below-ground invertebrates (McKenzie et al., 2013). Altered rainfall can have variable effects on the interactions between invertebrates. For example, Staley et al. (2007) showed that a root chewer can negatively affect the performance of an aboveground leaf miner, but this relationship breaks down under drought conditions. In contrast, some interactions only become apparent under drought conditions; belowground herbivores have been shown to have positive effects on leaf mining flies under reduced rainfall compared with ambient conditions (Staley et al., 2008). The nature of the water stress can also differentially impact abovebelowground interactions; Tariq et al. (2013) showed that under a moderate drought stress, root herbivory increased plant chemical defenses, reducing the performance and abundance of a specialist herbivore. In highly drought stressed plants, however, this response did not occur.

Future precipitation regimes may therefore have a range of impacts on above- and below-ground invertebrates, and potentially modify linkages and interactions between these two groups. Experiments often use simplified pot and lab experiments, which are useful for teasing apart causal relationships but cannot fully incorporate synergies between the direct and indirect effects of altered precipitation across multiple trophic levels. Above- and below-ground linkages observed in such experiments, for instance, do not necessarily represent what happens in field situations (e.g., Vandegehuchte et al., 2010; but see Johnson et al., 2013). Community-level field experiments that incorporate background climatic variation and simulate a range of precipitation regimes, looking beyond just reduced and increased rainfall scenarios (e.g., seasonal and frequency related changes), could prove provide a more realistic simulation of such climatic change (Jentsch et al., 2007). Nonetheless, measuring changes in both above- and below-ground communities is destructive and imposes legacy effects so these experiments provide a 'snapshot' of above- and below-ground community changes rather than detailed temporal information.

We aimed to test how above- and below-ground grassland invertebrate populations were affected by contrasting future rainfall scenarios. To achieve this, we used a unique fieldbased community experiment in southeast Australia that applied ambient levels of precipitation together with four predicted precipitation patterns in a grassland ecosystem. We identified the effects of altered rainfall patterns on the abundance of invertebrate taxonomic groups, feeding guilds and the structure of the community as a whole. Additionally, we explored potential associations between above- and below-ground invertebrate communities and tested whether these were affected by altered precipitation patterns.

\section{MATERIALS AND METHODS}

\section{Experimental Site and Shelters}

We used the DRI-Grass (ㅁought and Root herbivore Impacts on a Grassland ecosystem) experimental platform for this research. This platform applies different rainfall regimes in a grassland ecosystem based in Richmond, New South Wales at 
the Western Sydney University Hawkesbury campus $\left(33^{\circ} 36^{\prime} 40^{\prime \prime}\right.$ S, $\left.150^{\circ} 44^{\prime} 26.5^{\prime \prime} \mathrm{E}\right)$. The DRI-Grass experiment consists of 48 permanent rain exclusion shelters $(1.8 \mathrm{~m} \times 2.0 \mathrm{~m}$ area; i.e., $3.6 \mathrm{~m} \times 3.6 \mathrm{~m}$ ) constructed from stainless steel frames and clear acrylic Perspex roofs. These shelters allow five rainfall scenarios to be simulated comprising 12 plots with (i) ambient (water applied in "real time" immediately after rainfall events), (ii) reduced amount ( $-50 \%$ of ambient), (iii) reduced frequency (no water for 21 days, followed by the total ambient rainfall applied in a single application) as well as six plots with, (iv) increased amount ( $+50 \%$ of ambient), and (v) summer drought (no rainfall for 13 weeks in the summer, 17 December to 27 March). Six plots of each of the 12 ambient, reduced amount and reduced frequency plots had been inoculated with scarab larvae as part of a concurrent, but separate, experiment which we accounted for as a covariate factor in our analysis (see Statistical analysis below). To assess differences between watering regimes, soil moisture readings are automatically taken every $15 \mathrm{~min}$ from TDR probes, and a daily mean was calculated (see Power et al., 2016 for full details of the DRI-Grass platform).

The grassland community beneath each shelter typically consisted of Axonopus fissifolius ( $\mathrm{C}_{4}$ grass), Cymbopogon refractus $\left(\mathrm{C}_{4}\right.$ grass), Eragrostis curvula ( $\mathrm{C}_{4}$ grass), Hypochaeris radicata (forb), Microlaena stipoides ( $\mathrm{C}_{3}$ grass), Paspalum dilatatum $\left(\mathrm{C}_{4}\right.$ grass), Plantago lanceolata (forb) and Setaria parviflora $\left(\mathrm{C}_{4}\right.$ grass). The soil is characterized as a sandy loam of moderate to low fertility, with a low organic matter content and low water holding capacity (see Barton et al., 2010 for full details). DRI-Grass was constructed in May 2013 and irrigation regimes commenced in June 2013. Aboveground plant material is harvested at the end of both the cool (i.e., October) and growing season (i.e., April) and plant biomass is estimated for each plot.

\section{Invertebrate Collection}

Three sampling methods were used to collect aboveground invertebrates, belowground macro-invertebrates and nematodes during 11-21 September 2015, prior to harvesting aboveground plant material in the following week. Vacuum ('G-vac' device) sampling, a proven quantitative technique (Brook et al., 2008), was used to capture aboveground invertebrates. The ' $\mathrm{G}$-Vac' sampler was an adapted petrol-powered device (SH 86C, Sithl AG \& Co. KG. Germany) fitted with an organza bag to catch invertebrates. This was passed under each rain exclusion shelter for $20 \mathrm{~s}$ in a zigzag pattern on full throttle. Samples were placed in zip lock bags and frozen until identification in the laboratory under a dissecting microscope (SZ51, Olympus, Japan). Belowground macro invertebrates were sampled by excavating two $25 \mathrm{~cm} \times 10 \mathrm{~cm} \times 20 \mathrm{~cm}$ (length $\times$ width $\times$ depth) trenches under each rain exclusion shelter. Macro invertebrates were stored into ethanol and frozen until identification in the laboratory. Both above- and below-ground samples were identified to at least order level, other than two groups which were identified to sub-class only (Acari and Collembola). A number of groups were also identified to sub order or family level, for more accurate identification of feeding guilds (see Supplementary Tables 1 and 2 for the groups identified and guild classifications).
Two additional soil cores $(3.5 \mathrm{~cm}$ diameter, $10 \mathrm{~cm}$ depth), one from each side of the plot, were collected for extraction of nematodes, at the same time as sampling belowground macro fauna. These were combined per plot to form a composite sample, gently homogenized and subsampled, with nematodes extracted from $50 \mathrm{~g}$ soil (wet weight) using a modified Baermann funnel technique (Baermann, 1917), over 3 days. The nematodes were then counted, assigned to feeding groups using morphological characteristics, and the numbers converted to individuals per $\mathrm{kg}$ dry soil. Nematode samples were collected as part of ongoing monitoring for interactive responses to herbivore addition and rainfall manipulations (i.e. Ambient, Reduced amount, and Reduced frequency treatment plots only), but were used in this study to investigate above- and below-ground linkages further.

\section{Statistical Analyses}

Statistical analyses were undertaken in $\mathrm{R}$, version 3.2.2 ( $\mathrm{R}$ Core Team, 2016). To confirm the effect of the applied watering treatment on soil moisture, we tested the effects of the applied rainfall regimes on soil moisture data from October 2014 to October 2015, using a repeated measures linear mixed effects model [package nlme, lme(); Pinheiro et al., 2016]. Repeated measures were used because of the recurring nature of soil moisture measurements, which were recorded as a proportion (\%) and therefore values were transformed prior to analysis using the logit() function (package car; Warton and Hui, 2011). The model used rainfall treatment and month as interactive fixed effects, with month nested within plot which was included as a random (mixed) effect. Interactive effects were tested first, followed by individual effects (Crawley, 2013). Custom post hoc comparisons were performed based on visual inspection (Figure 1) for significant factors [glht(), multcomp; Hothorn et al., 2008].

The effect of rainfall treatment on plant biomass from the October harvest was evaluated with a linear model using a Chi Square test, followed by a Tukey test.

Separate analyses were undertaken for each of the three different sampling methods (aboveground invertebrate vacuum sampling, belowground macro fauna and soil nematodes). Groups of invertebrates (separated by Order or feeding guild identity) that were captured infrequently - i.e., found in $<10 \%$ of samples or constituting $<50$ individuals in total - were excluded to permit statistical analysis (sensu Hillstrom and Lindroth, 2008). The effects of altered rainfall on invertebrate abundance were tested using generalized linear models (GLMs). Models contained a negative binomial error structure to account for overdispersion of the data [glm.nb(), MASS; Venables and Ripley, 2003] in all but three groups for which model dispersion parameters $<1.7$; these were analyzed using Poisson error structures. In order to determine the significance of the rainfall treatment, the full model described above was compared to a reduced model without rainfall treatment as a factor (likelihood ratio test). A concurrent experiment inoculated half of the ambient, reduced frequency and reduced amount plots with scarabs; therefore herbivore treatment 
was included in models as a covariate to account for this. Additionally, due to the documented effect of vegetation complexity on suction sampling efficiency, plant biomass was also included as a covariate when analyzing the aboveground abundance data (Brook et al., 2008; Facey and Torode, 2016). The model fit was determined by inspecting residual plots.

The effect of altered rainfall regimes on the community composition of invertebrates was analyzed using permutational multivariate analysis of variance [PERMANOVA, adonis() in the vegan package; Oksanen et al., 2016], with rainfall treatment included as a fixed effect.

A Pearson's correlation matrix was used to explore linkages between above- and below-ground invertebrate groups for each rainfall treatment separately. In order to avoid type II errors, only highly statistically significant $(P<0.01)$ results from the matrix were investigated further. A mixed model was used to show which of the highly significant correlations appeared to have a linear relationship; those that did not appear to have a linear relationship are not shown. Models used the abundance of two invertebrate groups that were significantly correlated, with the abundance of the aboveground group explained as a function of the abundance of the belowground group, with plot as a random effect. The fit of the model was assessed using residual plots and significance was determined using an ANOVA. Plots treated with additional root herbivory may have altered the relationships between above-below-ground invertebrates, so were not included in the analysis of above-belowground associations.

\section{RESULTS}

\section{Soil Moisture and Plant Responses}

Irrigation regime significantly affected soil moisture which varied by month, as shown by the interaction $\left(\mathrm{F}_{48,8700}=35.6\right.$, $P<0.001)$ (Figure 1). Plant biomass also varied between treatments $\left(\chi_{4}^{2}=10.069, P=0.039\right)$, with a greater plant biomass in the summer drought plots at the time of sampling, 5 months after the drought period ended (Figure 2). It was also in these plots that soil moisture decreased throughout the drought period, but returned to ambient levels in May, 1 month after the drought period ended (Figure 1; Table 1).

\section{Invertebrate Population Responses}

In total, 6,604 aboveground invertebrates and 3,736 belowground macro invertebrates were counted and identified. A number of aboveground invertebrate taxa varied significantly in abundance between rainfall treatments (Table 2). Specifically, summer drought increased the abundance of invertebrates in the Orders Hemiptera, Orthoptera, Diptera, and Acari (Table 2; Figures 3A-D). In terms of functional guilds, summer drought positively affected the abundance of sucking herbivores, parasitoids, chewing herbivores, and detritivores (Figures 4AD). The abundance of Collembola also varied between rainfall regimes, with a greater number found under the increased amount treatment (Table 2; Figure 3E). A number of taxonomic groups and guilds did not vary in abundance significantly between treatments (Table 2). The community composition of aboveground invertebrates varied significantly between rainfall treatments (Table 3). Despite a number of groups varying in their abundance, sucking herbivores and their associated order Hemiptera largely accounted for the change in community composition because of their very large increase in abundance under summer drought (Figures 3 and 4).

Belowground Hymenoptera (Formicidae) and their associated guild, scavengers, were the only belowground groups for which abundance was significantly affected by altered rainfall regimes (Table 2, Figures 5A,B). The community composition of belowground fauna was not detectably affected by the rainfall treatments (Table 3).

\section{Exploring Above- and Below-Ground Linkages}

The abundances of aboveground Acari and belowground Coleoptera were positively correlated under ambient and increased amount rainfall scenarios (Figures 6A,B). The same relationship was observed for their associated guilds, scavengers and root chewers, under ambient rainfall regimes only (Figure 7A). A number of other relationships were only observed under ambient rainfall, including positive correlations between aboveground Collembola and belowground Megadrilacea (Figure 6C), and aboveground parasitoids and belowground fungal feeding nematodes (Figure 7B). Conversely, a negative relationship was found between the abundance of belowground fungal feeding nematodes and root chewers (Figure 7C). Additionally, the abundances of aboveground Collembola and belowground Hemiptera were positively correlated under the reduced amount treatment (Figure 6D), while a positive relationship was found between the abundance of aboveground detritivores and belowground sucking herbivores under summer drought conditions (Figure 7D). The abundance of a number of other aboveground and belowground invertebrates where found to have a strong correlation, however they did not appear to have a linear relationship (see Supplementary Table 3).

\section{DISCUSSION}

To our knowledge, this is the first report of a communitylevel field investigation of above- and below-ground invertebrate abundances across a range of potential future rainfall scenarios. In addition to reporting changes in the abundances of some invertebrates under altered rainfall, we showed that some above- and below-ground populations were tightly correlated, suggesting strong, yet precipitation-sensitive, linkages between these spatially separated organisms.

\section{Aboveground Invertebrate Responses}

Of the four rainfall regimes, summer drought had the greatest effect on aboveground invertebrates, increasing the abundance of a number of invertebrate groups at both a taxonomic and guild level. These plots also had the greatest plant biomass, which is 


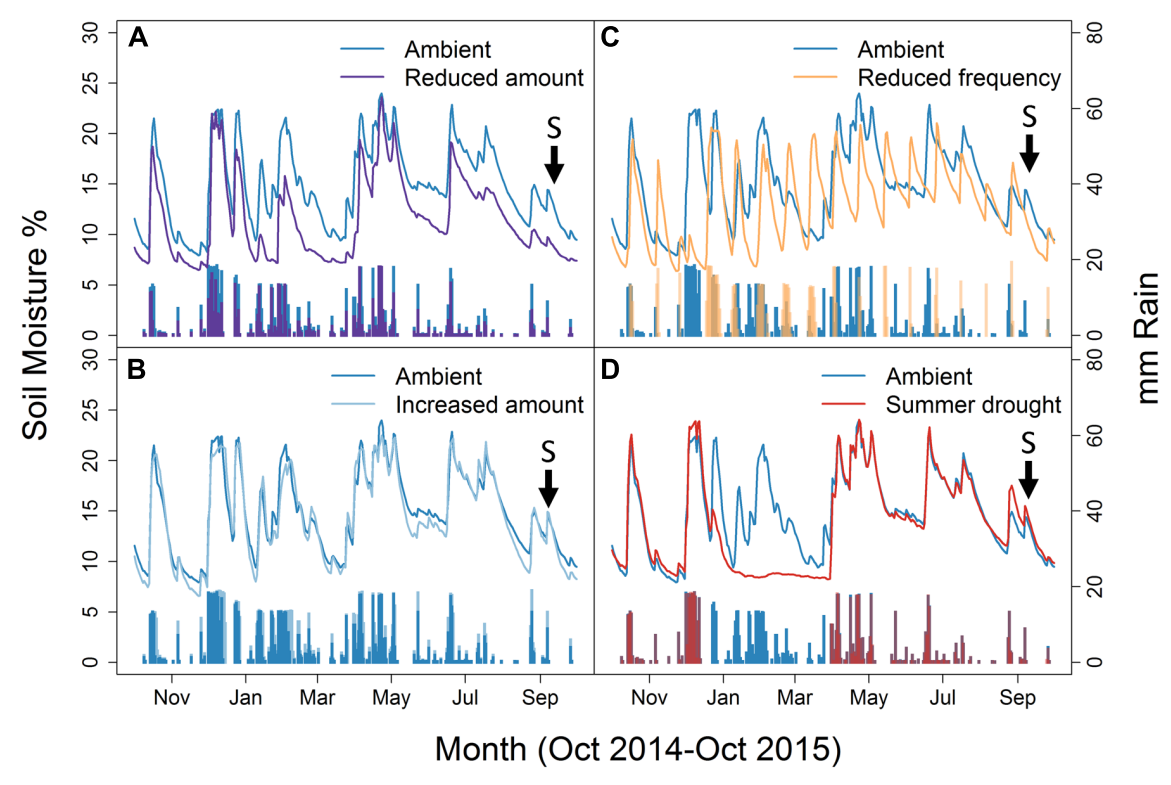

FIGURE 1 | Soil moisture and mm rain applied to ambient plots relative to; (A) Reduced amount, (B) Increased amount, (C) Reduced frequency, and (D) Summer drought. Lines show the Soil moisture, while the bars represent $\mathrm{mm}$ of rain applied. Arrows and 'S' indicates the time sampling took place. Weekly data shown from October 2014 to October 2015.

indicative of vigorous plant growth in the 5 months since the end of the summer drought. It is probable that there was more dieback in the 13 weeks without water during the growing season (January-March 2015). When precipitation returned to ambient levels, it is likely that resilient plants could take advantage of reduced competition and display vigorous growth. We propose that these results support the plant vigor hypothesis (Price, 1991). In particular, sucking herbivores (and Hemiptera) frequently show population spikes in spring because amino acids are being translocated for new growth (Dixon, 1998), so the more vigorous plant growth observed in summer drought plots benefited this group most.

Our observations of increased abundances of sucking herbivores in plots experiencing summer drought also has compatibilities with the pulsed-stress hypothesis (Huberty and Denno, 2004). Their meta-analysis demonstrated that sucking herbivores often benefit from plants subjected to intermittent water stress. In particular, reduced soil moisture often increases plant foliar nitrogen because pre-existing proteins can be hydrolysed, resulting in higher concentrations of free amino acids (Brodbeck and Strong, 1987). When rainfall resumes, phloem turgor pressure increases, allowing sucking herbivores (reliant on positive turgor pressure in the plant) to utilize the plant's improved nutritional quality (Huberty and Denno, 2004). However, 5 months had elapsed since irrigation was applied at ambient levels, so we consider that increases in foliar nitrogen wouldn't persist for so long. While it is possible that an increase in sucking herbivore abundance due to pulseddrought in April underpinned larger populations observed in September, we find the plant vigor hypothesis more convincing, particularly since we also saw increases in other groups (e.g., chewing herbivores and detritivores). Moreover, our reduced

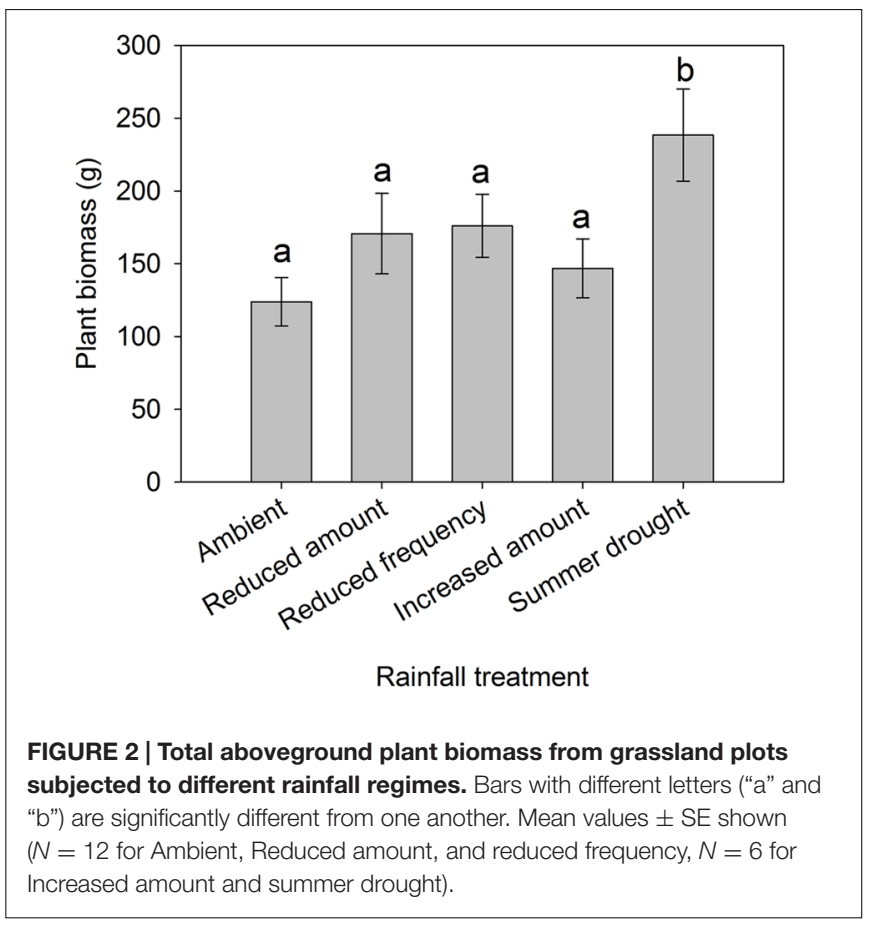

frequency treatment (intermittent periods of drought, followed by larger rainfall events) is probably more similar to the pulsed-drought described by Huberty and Denno (2004), and we saw little impact on sap-suckers and Hemiptera in these plots.

The abundance of parasitoids also increased under summer drought, suggesting that parasitoids are tracking their 
TABLE 1 | Results from linear model post hoc test showing differences in soil moisture between ambient and summer drought plots.

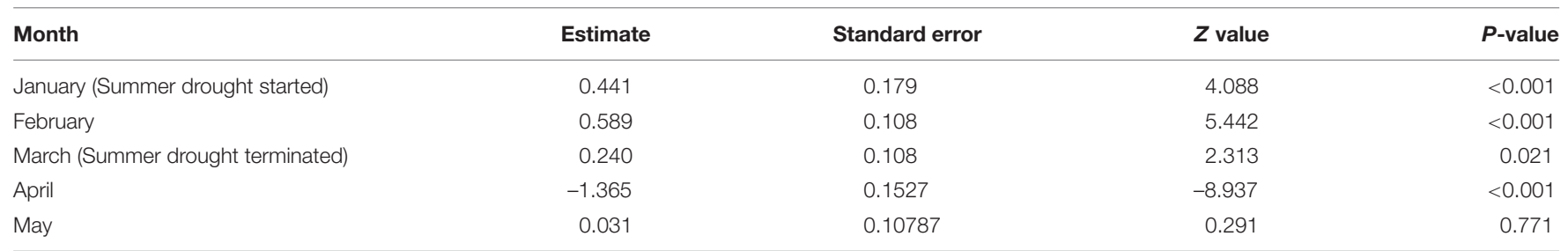

Soil moisture is shown for months during the summer drought and 2 months after the summer drought period.

TABLE 2 | Results from general linear model, showing how absolute abundance varied between rainfall treatments.

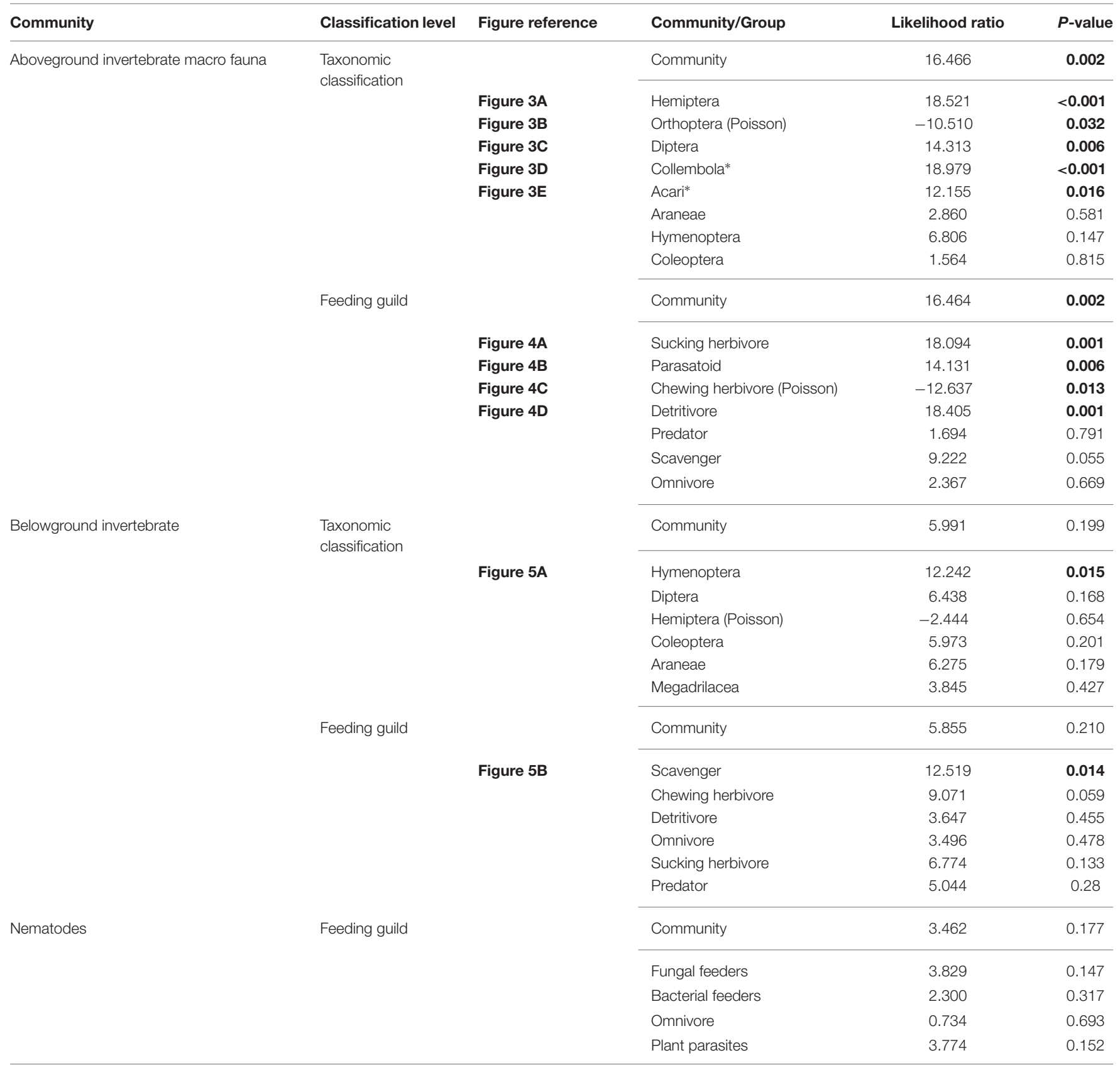

All groups have been classified to an order level with the exception of these groups marked with* which have been classified to subclass. Statistically significant differences indicated in bold. 

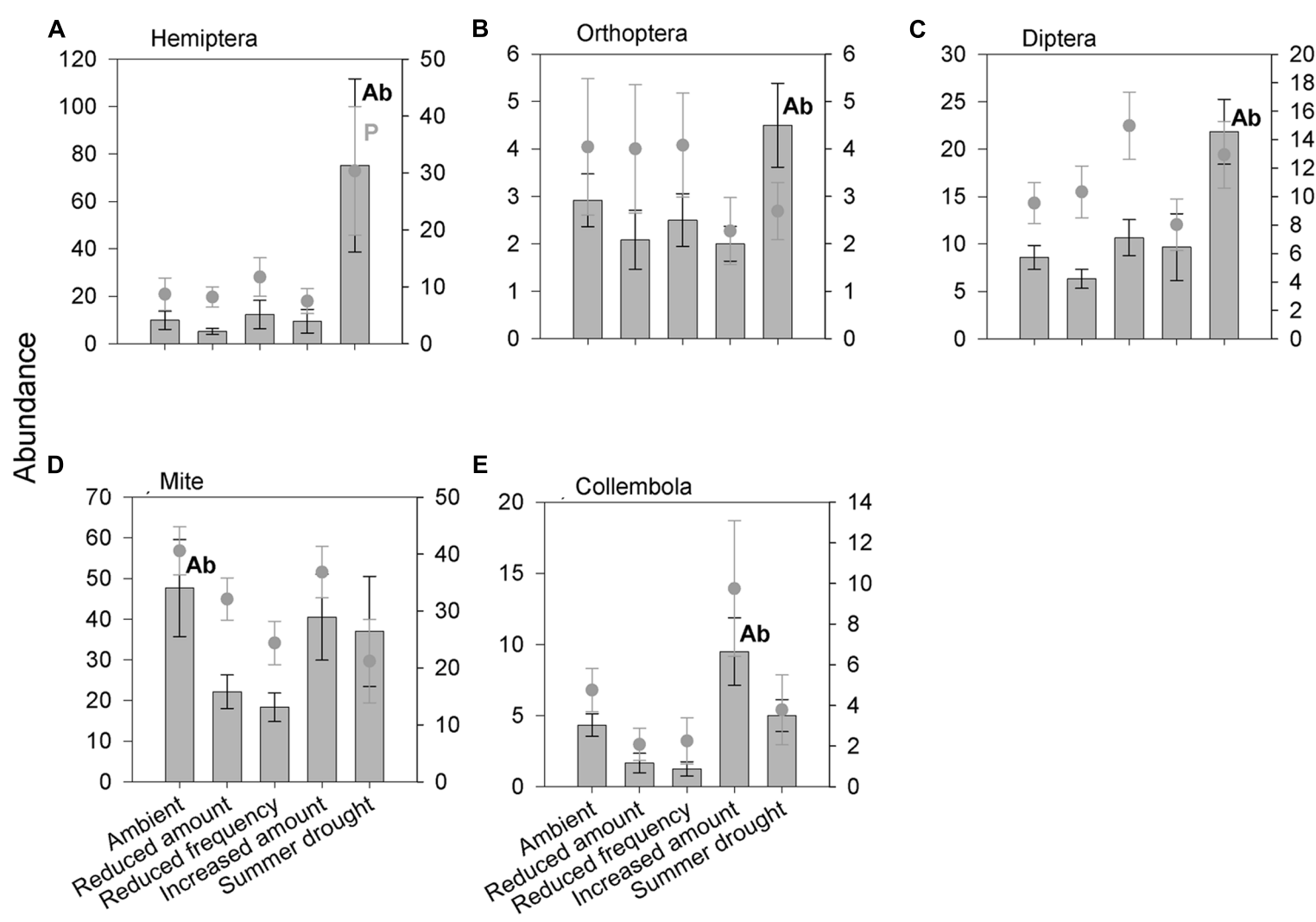

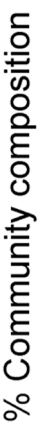

Rainfall regime

FIGURE 3 | Aboveground invertebrate taxonomic groups (A) Hemiptera, (B) Orthoptera, (C) Diptera, (D) Mite and (E) Collembola were significantly affected by rainfall regime in terms of absolute abundance and/or change in proportion of the community. Bars show absolute abundance and points indicate the proportion of the overall community represented by the group. Statistically significant changes in absolute abundance indicated 'Ab' (see Table $\mathbf{2}$ for corresponding analysis). Taxonomic groups most influencing the reported change in community composition indicated 'P'. Mean values \pm SE shown ( $N=6)$.

TABLE 3 | Results from multivariate permutational analysis (PERMANOVA) showing the effect of rainfall treatment on the community composition of above- and below-ground invertebrates at both order and guild level.

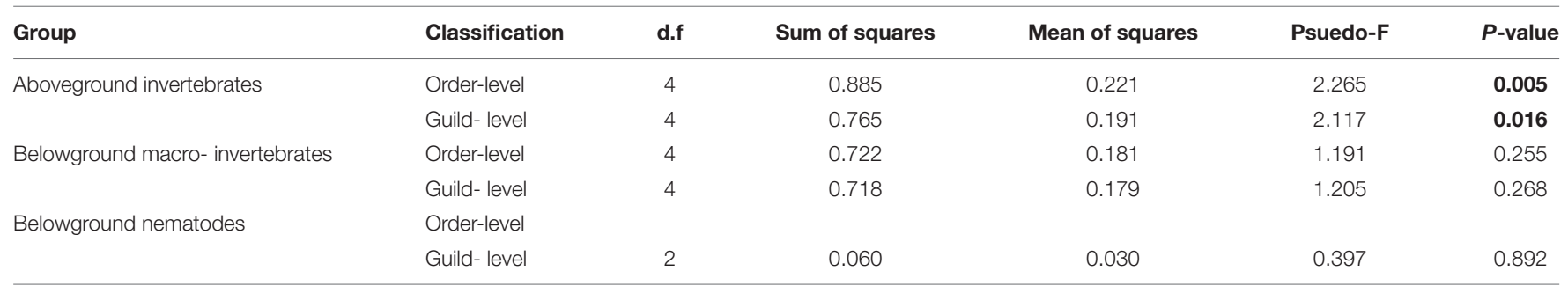

Belowground macro invertebrates and nematodes were analyzed separately due to differences in sampling techniques.

Hemipteran hosts' population dynamics, as found in Zhu et al. (2014). Indeed, the abundance of parasitoids was positively correlated with sucking herbivores in summer drought plots, providing further evidence that these insects are tracking the abundance of their hosts.

The general increase in herbivores under summer drought associated with the higher levels of cool season plant growth may explain the increased abundance of detritivores as well. In particular, the greater quantity of insect cadavers, frass and plant detritus is likely to have increased resources for this group. Increases in fungus gnats (Diptera), rather than Collembola, underpinned the increase in detritivores. Instead, the abundance of Collembola was more sensitive to increases in rainfall as evidenced by their greater numbers under the increased amount treatment compared with reduced frequency and amount plots. The abundance of Acari was reduced within the reduced frequency plots, indicating that this group may be sensitive to reductions in water availability. Both Collembola and 


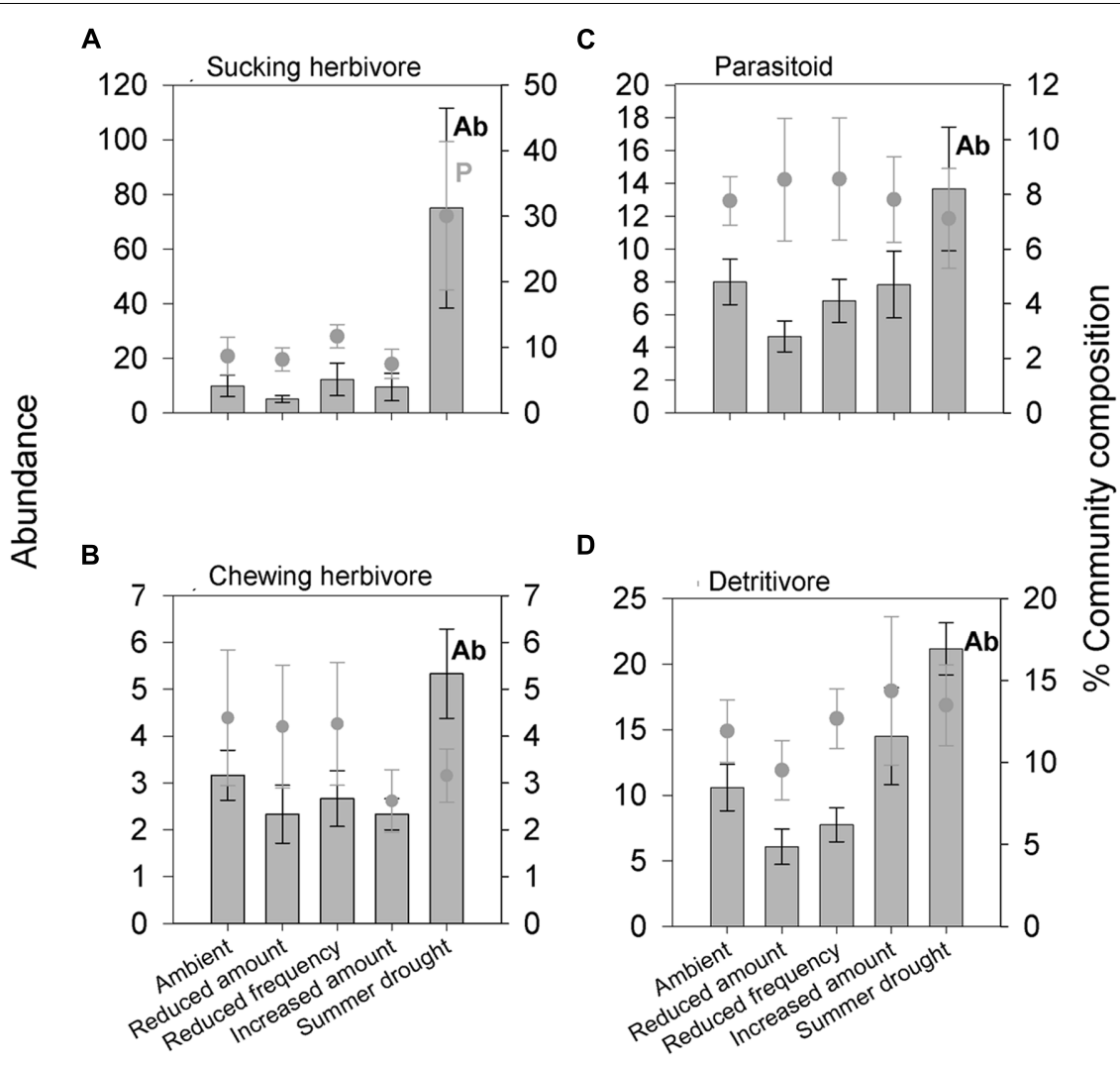

Rainfall regime

FIGURE 4 | Aboveground invertebrate feeding guilds (A) sucking herbivore, (B) parasitoid, (C) chewing herbivore, and (D) detritivores significantly affected by different rainfall regimes in terms of absolute abundance and/or change in proportion of the community. Bars show absolute abundance and points indicate the proportion of the overall community represented by the group. Statistically significant changes in absolute abundance indicated 'Ab' (see Table 2 for corresponding analysis). Feeding guilds most influencing the reported change in community composition indicated 'P'. Mean values $\pm \mathrm{SE}$ shown ( $N=6$ ).

\section{A}

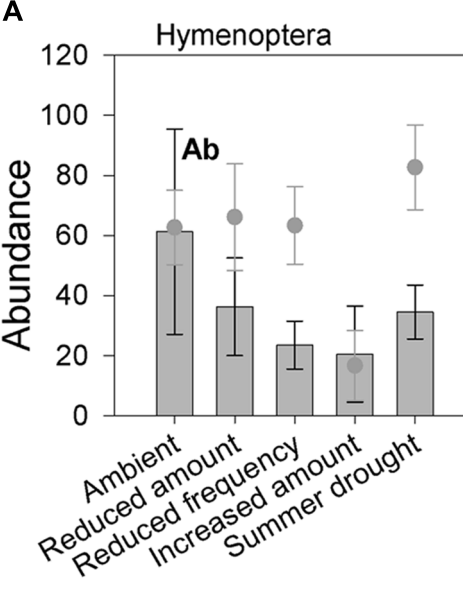

B

70
60
50
40
30
20
10

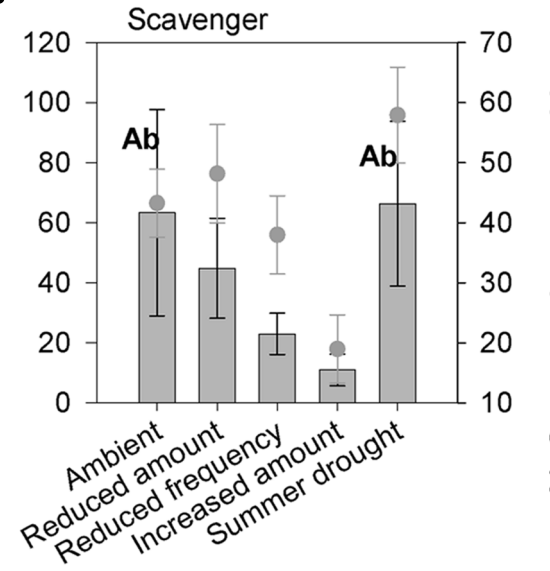

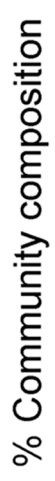

\section{Rainfall regime}

FIGURE 5 | Belowground invertebrate taxonomic groups and feeding guilds (A) Hymenoptera and (B) Scavengers significantly affected by different rainfall regimes in terms of absolute abundance. Bars show absolute abundance and points indicate the proportion of the overall community represented by the group. Statistically significant changes in absolute abundance indicated 'Ab' (see Table 2 for corresponding group. Mean values \pm SE shown ( $N=6$ ). 
A

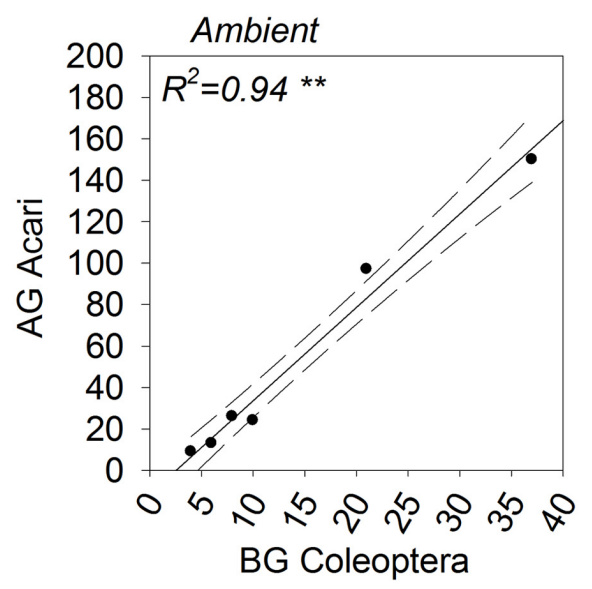

C

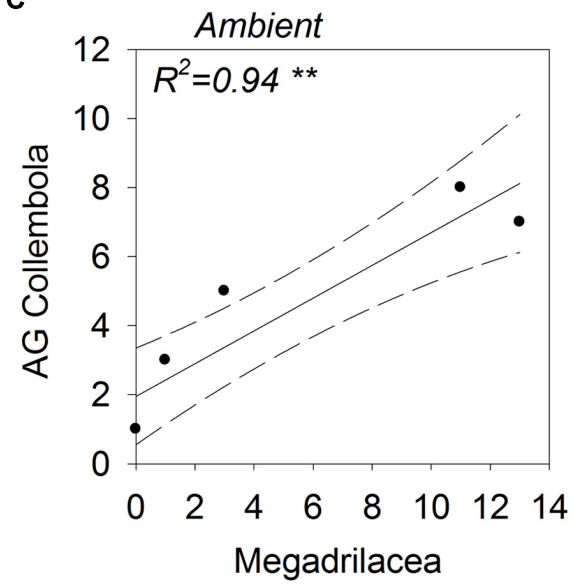

B

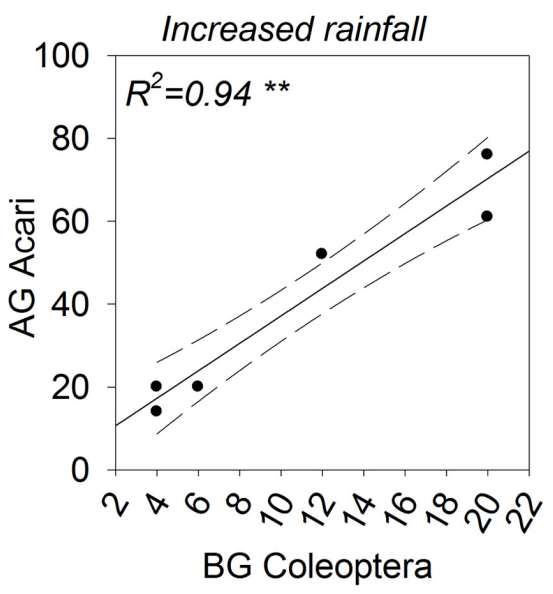

D

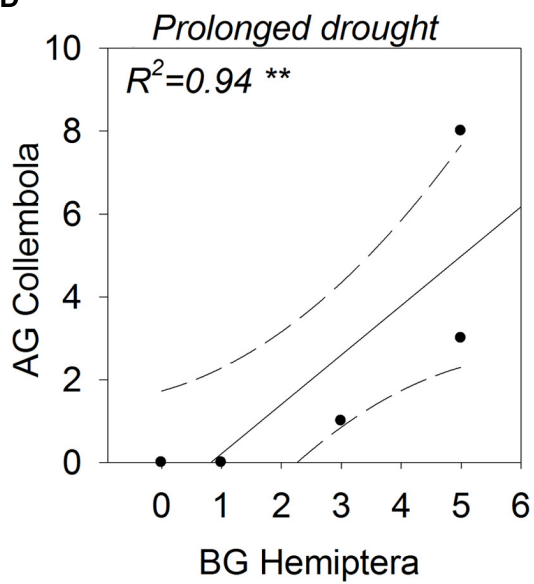

FIGURE 6 | Above- (shown on the $y$-axis) and below-ground (shown on the $x$-axis) taxonomic groups showing statistically significant correlations in abundance; (A) Acari (aboveground) and Coleoptera (belowground), (B) Acari (aboveground) and Coleoptera (belowground), (C) Collembola (aboveground) and Megadrilacea (belowground), and (D) Collembola (aboveground) and Hemiptera (belowground). The rainfall regime under which the correlation occurred indicated for each panel. Solid lines indicate model predicted values; points represent actual values and dashed lines represent $95 \%$ confidence intervals.

Acari could have been negatively affected directly by the low soil moisture in the reduced rainfall plots (Convey et al., 2002; Lindberg et al., 2002; A'Bear et al., 2014).

In addition to changes in absolute abundance, the community composition of invertebrates also varied between rainfall treatments. Despite a number of aboveground invertebrates increasing in absolute abundance under summer drought plots, the observed changes in community composition aboveground were driven primarily by increases in the relative abundance of sucking herbivores (Hemiptera).

\section{Below-Ground Invertebrate Responses}

Altered rainfall regimes had little measurable effect on the belowground community, with no change in community composition found between treatments. Altered precipitation patterns may have affected belowground invertebrates less because they have a host of adaptations to mitigate changes in their microclimate, such as utilizing metabolic water, moving through the soil profile and constructing earthen chambers (Barnett and Johnson, 2013). Only Hymenoptera (Formicidae) and their associated scavenger guild were affected by altered rainfall, showing reduced abundance in plots receiving increased amounts of rainfall. This could be the result of negative effects of increased soil humidity on ants, as suggested by Seal and Tschinkel (2010).

\section{Above- and Below-Ground Linkages}

A number of above- and below-ground linkages were observed under ambient rainfall, but dissipated under altered rainfall regimes. The reasons for such linkages occurring and their decoupling under altered rainfall patterns remain unknown, and we stress that explanations postulated below are highly speculative. They do, however, provide the basis for formulating hypotheses to direct future work. 

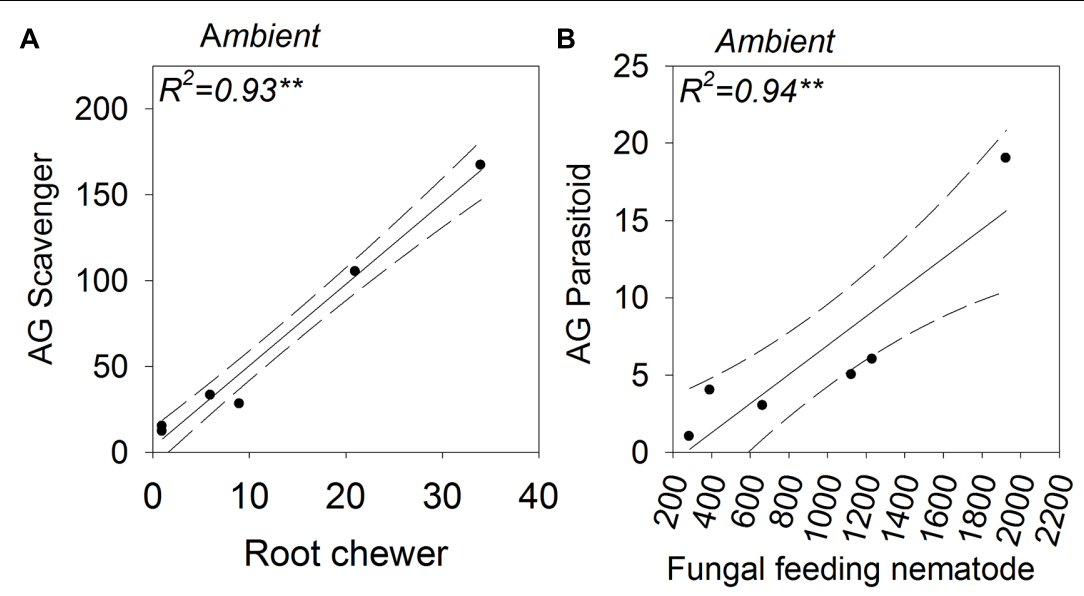

C

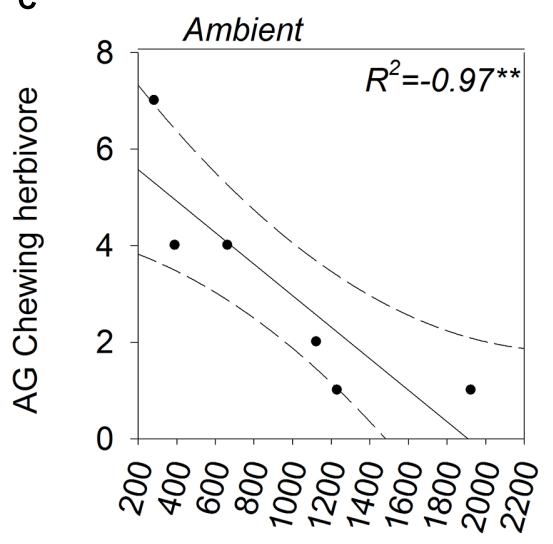

Fungal feeding nematode
D

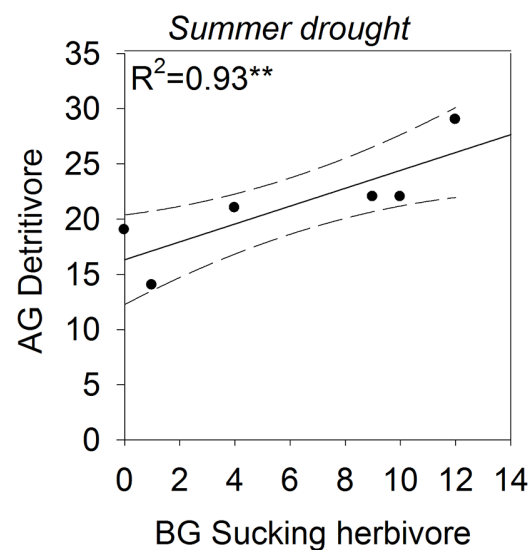

FIGURE 7 | Above- (shown on the $y$-axis) and below-ground (shown on the $x$-axis) feeding guilds showing statistically significant correlations in abundance; (A) scavengers (aboveground) and root chewers (belowground), (B) parasitoids (aboveground) and fungal feeding nematodes (belowground), (C) chewers (aboveground) and fungal feeding nematodes (belowground), and (D) detritivores (aboveground) and suckers (belowground). The rainfall regime under which the correlation occurred indicated for each panel. Solid lines indicate model predicted values; points represent actual values and dashed lines represent $95 \%$ confidence intervals.

The positive relationship between the abundance of Acari (aboveground) and Coleoptera (belowground), for example, was only observed under ambient and increased amount plots. Root chewing herbivores like Coleopteran larvae can induce plants to reallocate resources aboveground, moving resources away from the site of attack, termed 'resource sequestration' (Orians et al., 2011; van Dam and Heil, 2011). Improved nutritional quality of plant detritus aboveground could then benefit scavengers, like Acari. The breakdown of these relationships could be a result of changes in the composition of species within these groups under altered rainfall regimes, even if the groups' abundance didn't change. Similarly, changes in plant community traits under drought (e.g., greater root:shoot ratios, accelerated senescence and litter production, and shifts in nutrient stoichiometry [Dijkstra et al., 2012]) could influence the plant-mediated aboveground-belowground interactions.

Collembola (aboveground) and Megadrilacea (belowground) were positively correlated under only ambient rainfall.
Both groups are detritivores therefore their abundances may simply reflect similar responses to variations in the detritus inputs in ambient plots, resulting in a correlation. Supplementing detrital material has, for example, been shown to increase detritivore abundance (Halaj and Wise, 2002). Altered rainfall may have negatively affected aboveground detritivores to a greater extent than belowground detritivores, decoupling the association between the two groups.

The negative relationship between fungal feeding nematodes (belowground) and chewing herbivores (aboveground) was also only present under ambient rainfall; this finding may possibly be mediated via mycorrhizal communities. Fungal feeding nematodes can indicate the presence of mycorrhizal fungi in the soil (Landesman et al., 2011). Mycorrhizal infection frequency increases plant resistance to herbivory aboveground (Fontana et al., 2009), thereby potentially reducing the abundance of generalist chewing herbivores (Gange et al., 2002). 
More information on treatment effects on mycorrhizal root colonization and community composition would be required to support this theory. Altered precipitation regimes didn't result in the association between herbivores and fungal feeding nematodes. Variation in the composition of mycorrhiza species, as well as colonization rates, under different rainfall regimes could have altered their effect on plant chemistry and the aboveground invertebrate community.

\section{CONCLUSION}

This study indicates that changes in precipitation, specifically changes in the seasonality of rainfall, are likely to cause alterations in the abundance and composition of aboveground, and to a lesser extent belowground, invertebrate communities. In particular, summer drought resulted in outbreaks of sucking herbivores, which probably underpinned the concurrent increase in the abundance of parasitoids. However, this study represents a 'snapshot' of impacts on invertebrate communities in spring only and patterns may be different during the growing season. It remains to be determined whether these changes persist over the longer term or whether communities return to a state of equilibrium. These findings, together with the precipitationsensitive linkages outlined in this study, do, however, lend further empirical support to the idea that climate change will modify grassland invertebrate communities with potential cascading effects. Moreover, linkages between above- and below-ground communities may be modified by climate change (McKenzie et al., 2013), which we propose can be termed 'climatic decoupling.'

\section{REFERENCES}

A'Bear, A. D., Jones, T. H., and Boddy, L. (2014). Potential impacts of climate change on interactions among saprotrophic cord-forming fungal mycelia and grazing soil invertebrates. Fungal Ecol. 10, 34-43. doi: 10.1016/j.funeco.2013.01.009

Baermann, G. (1917). Eine Einfache Methode zur Auffindung vor Ankylostomum (Nematoden). Larven in Erdproben. Batavia: Genesk Lab Feestbundel, 41-47.

Barnett, K. L., and Facey, S. L. (2016). Grasslands, invertebrates, and precipitation: a review of the effects of climate change. Front. Plant Sci. 7:1196. doi: 10.3389/fpls.2016.01196

Barnett, K., and Johnson, S. N. (2013). Living in the soil matrix: abiotic factors affecting root herbivores. Adv. Insect Physiol. 45, 1-52. doi: 10.1016/B978-0-12417165-7.00001-5

Barton, C. V. M., Ellsworth, D. S., Medlyn, B. E., Duursma, R. A., Tissue, D. T., Adams, M. A., et al. (2010). Whole-tree chambers for elevated atmospheric $\mathrm{CO} 2$ experimentation and tree scale flux measurements in south-eastern Australia: the Hawkesbury forest experiment. Agric. For. Meteorol. 150, 941-951. doi: 10.1016/j.agrformet.2010. 03.001

Berridge, M. (2012). Osmoregulation in terrestrial arthropods. Chem. Zool. 5, 287-320.

Brodbeck, B., and Strong, D. (1987). "Amino acid nutrition of herbivorous insects and stress to host plants," in Insect Outbreaks: Ecological and Evolutionary Perspectives, eds P. Barbosa and J. C. Schultz (New York, NY: Academic Press), $347-364$.

Brook, A. J., Woodcock, B. A., Sinka, M., and Vanbergen, A. J. (2008). Experimental verification of suction sampler capture efficiency in grasslands

\section{AUTHOR CONTRIBUTIONS}

SJ conceived the experimental design. MT, KB, UN, SP, and SF collected field data. MT and SF analyzed the data with help from $\mathrm{KB}$ and SJ. MT wrote the paper with the assistance of $\mathrm{KB}, \mathrm{SF}, \mathrm{UN}$, SP, and SJ.

\section{FUNDING}

Research for the paper was funded by the Hawkesbury Institute for the Environment and the Australian Research Council (DP140100363). UN is supported by funding from the Australian Research Council (DP150104199).

\section{ACKNOWLEDGMENTS}

The research was undertaken by MT as part of a Professional Training Year at the Hawkesbury Institute for the Environment. This paper is part of a series of articles from the Ninth Australasian Congress of Grassland Invertebrate Ecology and with sponsorship from HIE. We would like to thank Coline Deveautour, William Balmont, and Lanilà Hiltpold for their help in sampling the belowground invertebrate communities.

\section{SUPPLEMENTARY MATERIAL}

The Supplementary Material for this article can be found online at: http://journal.frontiersin.org/article/10.3389/fpls.2016.01468

of differing vegetation height and structure. J. Appl. Ecol. 45, 1357-1363. doi: 10.1111/j.1365-2664.2008.01530.x

Convey, P., Pugh, P. J. A., Jackson, C., Murray, A. W., Ruhland, C. T., Xiong, F. S., et al. (2002). Response of Antarctic terrestrial microarthropods to long-term climate manipulations. Ecology 83, 3130-3140. doi: 10.1890/00129658(2002)083[3130:ROATMT]2.0.CO;2

Crawley, M. J. (2013). The R Book. West Sussex: John Wiley \& Sons.

Curry, J. P. (1994). Grassland Invertebrates. London: Chapman and Hall.

Daily, G. (ed.) (1997). Nature's Services: Societal Dependence on Natural Ecosystems. Washington, DC: Island Press.

Dijkstra, F. A., Pendall, E., Morgan, J. A., Blumenthal, D. M., Carrillo, Y., LeCain, D. R., et al. (2012). Climate change alters stoichiometry of phosphorus and nitrogen in a semiarid grassland. New Phytol. 196, 807-815. doi: 10.1111/j.14698137.2012.04349.x

Dixon, A. F. G. (1998). Aphid Ecology. An optimization Approach. London: Chapman \& Hall.

Facey, S. L., and Torode, M. D. (2016). "An assessment of the effect of sward height on suction sampling efficiency for the capture of grassland invertebrates using a G-Vac device," in Proceedings of the Ninth Australasian Conference on Grassland Invertebrate Ecology, ed. S. N. Johnson (Richmond, NSW: Western Sydney University Press).

Fontana, A., Reichelt, M., Hempel, S., Gershenzon, J., and Unsicker, S. B. (2009). The effects of arbuscular mycorrhizal fungi on direct and indirect defense metabolites of Plantago lanceolata L. J. Chem. Ecol. 35, 833-843. doi: 10.1007/s10886-009-9654-0

Gange, A. C., Stagg, P. G., and Ward, L. K. (2002). Arbuscular mycorrhizal fungi affect phytophagous insect specialism. Ecol. Lett. 5, 11-15. doi: 10.1046/j.14610248.2002.00299.x 
Gantz, J. D., and Lee, R. E. Jr. (2015). The limits of drought-induced rapid cold-hardening: extremely brief, mild desiccation triggers enhanced freeze-tolerance in Eurosta solidaginis larvae. J. Insect Physiol. 73, 30-36. doi: 10.1016/j.jinsphys.2014.12.004

Garnaut, R. (2011). The Garnaut Review 2011 - Australia in the Global Response to Climate Change. Cambridge: Cambridge University Press.

Gibson, D. J. (2009). Grasses and Grassland Ecology. Oxford: Oxford University Press.

Halaj, J., and Wise, D. H. (2002). Impact of a detrital subsidy on trophic cascades in a terrestrial grazing food web. Ecology 83, 3141-3151. doi: 10.2307/ 3071849

Hillstrom, M. L., and Lindroth, R. L. (2008). Elevated atmospheric carbon dioxide and ozone alter forest insect abundance and community composition. Insect Conserv. Divers. 1, 233-241. doi: 10.1111/j.1752-4598.2008.00031.x

Hothorn, T., Bretz, F., and Westfall, P. (2008). Simultaneous inference in general parametric models. Biom. J. 50, 346-363. doi: 10.1002/bimj.200810425

Huberty, A. F., and Denno, R. F. (2004). Plant water stress and its consequences for herbivorous insects: a new synthesis. Ecology 85, 1383-1398. doi: 10.1890/030352

IPCC (2014). "Climate change 2014 - impacts, adaptation and vulnerability. Part A: global and sectoral aspects," in Contribution of Working Group II to the Fifth Assessment Report of the Intergovernmental Panel on Climate Change, eds C. B. Field, V. R. Baros, D. J. Dokken, K. J. Mach, M. D. Mastrandrea, T. E. Bilir, et al. (Cambridge: Cambridge University Press), 1132.

Jentsch, A., Kreyling, J., and Beierkuhnlein, C. (2007). A new generation of climatechange experiments: events, not trends. Front. Ecol. Environ. 5, 365-374. doi: 10.1890/1540-9295(2007)5[365:ANGOCE]2.0.CO;2

Johnson, S. N., Gregory, P. J., McNicol, J. W., Oodally, Y., Zhang, X., and Murray, P. J. (2010). Effects of soil conditions and drought on egg hatching and larval survival of the clover root weevil (Sitona lepidus). Appl. Soil Ecol. 44, 75-79. doi: 10.1016/j.apsoil.2009.10.002

Johnson, S. N., Mitchell, C., Thompson, J., and Karley, A. J. (2013). Downstairs drivers - root herbivores shape communities of above-ground herbivores and natural enemies via changes in plant nutrients. J. Anim. Ecol. 82, 1021-1030. doi: 10.1111/1365-2656.12070

Koricheva, J., Larsson, S., and Haukioja, E. (1998). Insect performance on experimentally stressed woody plants: a meta-analysis. Annu. Rev. Entomol. 43, 195-216. doi: 10.1146/annurev.ento.43.1.195

Landesman, W. J., Treonis, A. M., and Dighton, J. (2011). Effects of a oneyear rainfall manipulation on soil nematode abundances and community composition. Pedobiologia 54, 87-91. doi: 10.1016/j.pedobi.2010.10.002

Lindberg, N., Engtsson, J. B., and Persson, T. (2002). Effects of experimental irrigation and drought on the composition and diversity of soil fauna in a coniferous stand. J. Appl. Ecol. 39, 924-936. doi: 10.1046/j.13652664.2002.00769.x

Losey, J. E., and Vaughan, M. (2006). The economic value of ecological services provided by insects. Bioscience 56, 311-323. doi: 10.1641/00063568(2006)56[311:tevoes] 2.0.co;2

McKenzie, S. W., Hentley, W. T., Hails, R. S., Jones, T. H., Vanbergen, A. J., and Johnson, S. N. (2013). Global climate change and aboveground-belowground insect interactions. Front. Plant Sci. 4:412. doi: 10.3389/fpls.2013.00412

Oksanen, J., Blanchet, F. G., Kindt, R., Legendre, P., Minchin, P. R., O’Hara, R. B., et al. (2016). Vegan: Community Ecology Package; $R$ Package version 2.0-0. Available at: http://cran.r-project.org [accessed 1 July, 2016].

Orians, C. M., Thorn, A., and Gomez, S. (2011). Herbivore-induced resource sequestration in plants: why bother? Oecologia 167, 1-9. doi: 10.1007/s00442011-1968-2

Pinheiro, J., Bates, D., DebRoy, S., Sarkar, D., and R Core Team (2016). nlme: Linear and Nonlinear Mixed Effects Models. R Package Version 3.1-128.
Available at: http://CRAN.R-project.org/package=nlme [accessed 1 July, 2016].

Power, S. A., Barnett, K. L., Ochoa-Huesco, R., Facey, S. L., Gibson-Forty, E., Nielsen, U. N., et al. (2016). DRI-Grass: a new experimental platform for addressing grassland ecosystem responses to future precipitation scenarios in south-east Australia. Front. Plant Sci 7:1373. doi: 10.3389/fpls.2016. 01373

Price, P. W. (1991). The plant vigour hypothesis and herbivore attack. Oikos 62, 244-251. doi: $10.2307 / 3545270$

Price, P. W. (2003). Macroevolutionary Theory on Macroecological Patterns. Cambridge: Cambridge University Press.

R Core Team (2016). A Language and Environment for Statistical Computing. Vienna: R Foundation for Statistical Computing.

Seal, J. N., and Tschinkel, W. R. (2010). Distribution of the fungus-gardening ant (Trachymyrmex septentrionalis) during and after a record drought. Insect Conserv. Divers. 3, 134-142. doi: 10.1111/j.1752-4598.2010.00085.x

Staley, J. T., Hodgson, C. J., Mortimer, S. R., Morecroft, M. D., Masters, G. J., Brown, V. K., et al. (2007). Effects of summer rainfall manipulations on the abundance and vertical distribution of herbivorous soil macro-invertebrates. Eur. J. Soil Biol. 43, 189-198. doi: 10.1016/j.ejsobi.2007.02.010

Staley, J. T., Mortimer, S. R., and Morecroft, M. D. (2008). Drought impacts on above-belowground interactions: do effects differ between annual and perennial host species? Basic Appl. Ecol. 9, 673-681. doi: 10.1016/j.baae.2007.10.006

Tariq, M., Rossiter, J. T., Wright, D. J., and Staley, J. T. (2013). Drought alters interactions between root and foliar herbivores. Oecologia 172, 1095-1104. doi: 10.1007/s00442-012-2572-9

van Dam, N. M., and Heil, M. (2011). Multitrophic interactions below and above ground: en route to the next level. J. Ecol. 99, 77-88. doi: 10.1111/j.13652745.2010.01761.x

Vandegehuchte, M. L., de la Peña, E., and Bonte, D. (2010). Interactions between root and shoot herbivores of Ammophila arenaria in the laboratory do not translate into correlated abundances in the field. Oikos 119, 1011-1019. doi: 10.1111/j.1600-0706.2009.18360.x

Venables, W. N., and Ripley, B. D. (2003). Modern Applied Statistics with S. New York, NY: Springer.

Voigt, W., Perner, J., Davis, A. J., Eggers, T., Schumacher, J., Bahrmann, R., et al. (2003). Trophic levels are differentially sensitive to climate. Ecology 84, 2444-2453. doi: 10.1890/02-0266

Warton, D. I., and Hui, F. K. C. (2011). The arcsine is asinine: the analysis of proportions in ecology. Ecology 92, 3-10. doi: 10.1890/10-0340.1

Weisser, W. W., and Siemann, E. (2004). "The various effects of insects on ecosystem functioning," in Insects and Ecosystem Function, eds W. W. Weisser and E. Siemann (Berlin: Springer-Verlag), 3-24.

Zhu, H., Wang, D., Wang, L., Fang, J., Sun, W., and Ren, B. (2014). Effects of altered precipitation on insect community composition and structure in a meadow steppe. Ecol. Entomol. 39, 453-461. doi: 10.1111/een.12120

Conflict of Interest Statement: The authors declare that the research was conducted in the absence of any commercial or financial relationships that could be construed as a potential conflict of interest.

Copyright (c) 2016 Torode, Barnett, Facey, Nielsen, Power and Johnson. This is an open-access article distributed under the terms of the Creative Commons Attribution License (CC BY). The use, distribution or reproduction in other forums is permitted, provided the original author(s) or licensor are credited and that the original publication in this journal is cited, in accordance with accepted academic practice. No use, distribution or reproduction is permitted which does not comply with these terms. 